\title{
MANUAL INFAME... MAS ÚTIL, PARA ESCREVER UMA BOA PROPOSTA DE TESE OU DISSERTAÇÃO
}

Sandra Mara Corazza*

Contém ainda: 1) duas pequenas pérolas para escrever o traba tho final e sobreviver às sessões de defesa; 2) uma receita inédita para realizar uma tese foucaultiana e, na medida do possivel, manter a saúde física e mental, enquanto tudo isso se faz.

$$
* * *
$$

Todo mundo sabe o que é um manual. Quando abre um sabe o conteúdo que vai encontrar, pois ele é sempre $d e .$. ou para.... Assim como sabe o tipo de escrita que ali foi cometida. Um manual não precisa nem mesmo deve ser definido, explicado, contextualizado, senão deixa de ser manual e passa a ser artigo, ensaio, epopeia, lírica ou tragédia Deste, infame, só vou dizer uma coisa singela, pragmática, franca: ele nasceu por absoluta necessidade minha, como
* sandracorazza@terra.com.br

Professora titular da FACED/UFRGS. Experimentadora de

Escrileituras em Filosofia-Educação, Literatura-Artes, Currículo da Diferença, Didática da Tradução. Publicou, entre outros: Para uma filosofia do inferno na educação: Nietzsche, Deleuze e outros malditos afins (2002); Artistagens: filosofia da diferença e educação (2006), Os cantos de Fouror: escrileitura em filosofiaeducação (2008), Abecedário: educação da diferença (2009, coautoria), Dicionário das ideias feitas em educação (2011) e $O$ que se transcria em educação? (2013).

professora-orientadora de dissertações e teses pós-estruturalistas, na área temática "Pós-currículo, diferença e subjetivação de infantis" da linha de pesquisa "Filosofias da diferença e Educação” do Programa de Pós-Graduação em Educação da UFRGS. Porque cansei de falar as mesmas coisas, em sessões individuais ou coletivas de orientação: coisas que eram repetidas porque o que as impulsionava também era recorrente.

Você que começou a ler, de algum modo, está se deixando implicar neste manual. Não vou dizer que lhe poderá ser útil, já que poderia configurar uma propaganda enganosa. Sua prática é que decidirá. Para mim e meus orientandos está sendo útil. Se for proveitoso para você: que bom! Agora, atenção! Preciso lhe fazer uma advertência, a mesma que fiz a meus orientandos: se você perceber, sentir, entender, intuir, sacar que as orientações 
contidas no manual funcionam para padronizar, engessar, burocratizar suas produções... Então, será preciso desconstruir, desfazer, corromper, tornar o manual mais infame e baixo, bárbaro e grotesco, ainda. Porque o que vale, o que mais importa é o que cada um pode criar de produtivo e plausível para a "sua" proposta, dissertação, tese. Como eu pude inventar - até aqui, e sempre provisoriamente - isto, este manual, que minha prática de pesquisadora e orientadora me possibilitou escrever, com todos os seus limites e também devires.

\section{ESQUELETO DE UMA PROPOSTA}

\section{INTRODUÇÃO}

- Apresentar brevemente a temática e a teorização, o solo teórico da Proposta. Pode-se também resumir algo da problematização e do novo objeto a ser por ela constituído.

- No final desta seção, costuma-se realizar uma síntese de cada grande seção - evite a denominação "capítulo", que tem todo um formato específico, várias subdivisões, número extenso de páginas, etc. -, referindo o título e dizendo em que consiste, o que nela foi trabalhado.

- Esta parte apresenta diversas possibilidades de montagem: desde as mais breves, mais "burocráticas" - tipo as do artigos -, até as mais elaboradas, no sentido de já "analíticas". Pode ser dividida em subseções, se for esta a necessidade, no caso de existir material escrito sobrando.
- Cuidado com as repetições! Não é distinto e, aliás, é muito chato ler, no decorrer do texto, uma ou mais frases exatamente iguais às que já havíamos lido na Introdução. Seja criativo: mesmo que faltem ideias, não as repita do mesmo modo, encontre sinônimos, remonte as frases, varie os parágrafos.

- Outra coisa: pelo amor de deus ou do diabo, tanto faz, invente um título bonito e adequado a seu trabalho. Não precisamos mais escrever os aborrecidos e indigentes "Introdução" ou “Apresentação”, não é mesmo?

\section{APRESENTAÇÃO DO OBJETO "BRUTO"}

- Aqui, importa dar a conhecer, ao leitor, o objeto de pesquisa "em estado bruto".

- Apresentamos os "ditos e escritos" daquele objeto, daquele discurso, que sejam os das significações correntes, das ideias e sentimentos hegemônicos, dominantes, aceitos sem qualquer questionamento sobre seu valor, importância, elevação, nobreza.

- Apresentamos, também, as pesquisas já realizadas sobre tal objeto. Traçamos o mapa comum, que é, a princípio, o território de onde partimos para investigar o objeto.

- Para isso, realizamos sínteses, resumos dos argumentos, indicamos o que se repete, isolamos o mais importante, que nos importa desconstruir, na posterior atividade de análise. 
- Recheamos tal apresentação com fragmentos discursivos, seguidos das devidas aspas e referências.

- Fazemos tudo isto, com paciência, para poder fica claro que nada disso queremos pensar e dizer. Fazemos o movimento de nos filiar e, ao mesmo tempo, aqui, começamos a preparar a nossa des-filiação dos sentidos e práticas correntes.

- Importante: é preciso saber, nesta hora, que o objeto "bruto", que estamos dando a conhecer, pode ser objeto de muitos, que vivem numa determinada época, episteme, formação discursiva, sociedade, etc. Mas, que não é o "nosso" objeto, o objeto de nossa pesquisa pós-crítica. Porque, logo, logo, virá o "segundo objeto".

\section{PROBLEMATIZAÇÃO DO "OBJETO DE PESQUISA"}

- De posse da teorização que escolhemos, e dos conceitos que aí selecionamos, vamos, agora, "problematizar", isto é: fazer com o objeto bruto uma outra coisa. Vamos criar problemas, ali onde não existiam, onde nem se pensava que existissem. Ao menos, os que formos capazes de ver e formular.

- Há, então, dois objetos de pesquisa: 1) o “bruto”, que é o de todos. Que todos, ou muitos, podem escolher para investigar, estudar, discutir, analisar; e 2) o "nosso objeto de pesquisa", que, afinal, é aquele que questionamos e desfiguramos, re-lemos e re-escrevemos, desde a conceptualização escolhida.
- Aqui, nesta seção, levantamos "talvez", "pode ser que..." interrogamos, fazemos as perguntas de pesquisa, relativizamos os sentidos, suspeitamos das significações, desassossegamos o que parecia sossegado.

- É assim que criamos o "nosso" objeto de pesquisa, o "verdadeiro" objeto que vamos investigar.

- Exemplo. Se perguntarem: - Qual é o teu objeto de pesquisa? Rapidamente, respondemos: - A infância contemporânea. Não! Este é o objeto "bruto". O verdadeiro "objeto de pesquisa” a ser investigado é: - $\mathrm{O}$ dispositivo poder-saber-subjetividade de infantilização, no sentido foucaultiano. Pois, então, estamos diante de um outro objeto, de nosso legítimo objeto de pesquisa, ao qual atribuímos outros sentidos, pela via dos conceitos escolhidos. Já não pode mais ser aquele outro objeto, não costurado com a teoria que escolhemos, mas com outras teorias, que não a nossa.

\section{4. "REVISÃO" TEÓRICA}

- A pergunta mais importante a ser feita, nesta parte, para que seja produtiva, e para que a Proposta fique coerente, redonda, é: - O que é que eu vou usar?

- Há vários níveis dessa escolha de uso: 1) da perspectiva teórica, como um todo; 2) do autor, ou autores; 3) da "fase" conceitual e metodológica de cada autor; 4) de conceitos específicos, dentro da produção ou daquela fase. 
- Uma das coisas mais lamentáveis quando analiso um texto, para ir a uma Banca de Defesa, é me deparar com páginas e páginas de revisão teórica - na maioria das vezes, repetitiva, cansativa, mal escrita, incompleta -, e chegar ao fim da Proposta, ou mesmo da Dissertação/Tese, e constatar que, daquilo tudo, a criatura usou muito pouco.

- Isso é triste, porque fico pensando em todo aquele investimento, que poderia ter sido canalizado para uma análise, em maior profundidade, das ferramentas conceituais a serem efetivamente usadas na analítica.

- Não se tem, a cada Proposta, de partir, cada um, do marco zero. A produção do autor escolhido, na maioria das vezes, já foi - e muito bem - comentada, explicada, interpretada, discutida, por outros autores, geralmente bem mais competentes do que nós. Por que, então, não focar no que interessa para o nosso trabalho de pesquisa?

- É frequente, também, que a tal revisão teórica sofra um excesso tal que acabe ocupando mais páginas do que o próprio trabalho com o objeto.

- Se o gosto do candidato for este, o da revisão teórica ele pode pensar, então, em fazer um trabalho apenas conceitual - que, aliás, não é "apenas", porque é um trabalho complexo, que requer muito estudo e interlocução com muitos autores. Se não for esse o gosto, e se quiser realizar uma pesquisa "operatória", é preciso modular, enfocar, restringir ao que interessa.

- Quanto mais uma revisão teórica for interessada mais produtiva será!

- Há casos, mais difíceis, em que não se quer escrever uma seção de revisão teórica. Tudo bem. Só que, nesta condição, a costura entre teoria e objeto deverá acontecer desde o início da Proposta. Para tal, é preciso bastante tempo de estudo da teoria, imitação - no bom sentido - de como o autor operou com os seus objetos, bastante interação com o bruto, e conhecimento do próprio objeto de pesquisa. Embora eu prefira tal tipo de eliminação da revisão teórica, reconheço que é mais difícil, especialmente para o tempo, cada vez mais exíguo, do Mestrado. A não ser que a pessoa venha estudando aquilo tudo há, no mínimo, uns cinco, seis anos.

- Por último. Se optamos por realizar uma revisão teórica, por favor, que seja criativa, diferente, com ênfases originais, inesperadas. Não domestiquemos a produção do "pobre" autor, que, às vezes, levou uma vida inteira para estudar, pensar e escrever aquilo. Controlemos nosso excesso de academicismo, no mau sentido.

- Mas também há de se ter rigor, sempre. Nada de "vale tudo"! Nem de dar uma de "neófito", que se julga um "gênio" de compreensão relâmpago! 


\section{5. "EXERCÍCIO” ANALÍTICO}

- Pensem comigo: - O que é, por definição, um "exercício analítico"?

- Ora, do modo com vem sendo usado, é uma amostra, uma porção, uma parte da analítica a ser feita no trabalho final, que apresentamos à Banca Examinadora.

- Isto implica em quê? Na coisa mais difícil de todas, que é levantar, inventar, criar "unidades analíticas", que nos permitam olhar e dizer coisas diferentes das que são olhadas e vistas, com outros óculos e linguagem, sobre e acerca do objeto bruto

- Se vamos apresentar, no texto de nossa Proposta, um exercício analítico, já temos, evidentemente, de estar operando com nosso objeto. No mínimo, já temos de ter uma espécie de "mapa" das unidades que vamos usar.

- Uma das coisas mais maravilhosas, para mim, na função do pesquisador é sua "arbitrariedade". Ele escolhe, desde o início. Ele tem de escolher: desde o bruto, a teoria, a porção da teoria, as unidades. Arbitrariedade que, como todas, não é tão arbitrária assim, pois há algo aí que não sabemos: porque escolho isto e não aquilo, porque isto ou aquilo também "me escolheu”. E algo que é da ordem da responsabilidade ética de se ser um pesquisador/estudioso daquela teoria, autor objeto bruto, etc. Ou seja, como pesquisadores, estabelecemos uma relação de pertencimento a uma cultura, formada pelos que já estudaram e usaram tal teorização, pelos que já pesquisaram, de outros modos, o objeto bruto, etc. Fazemos, também, uma inserção nossa no próprio campo da prática de pesquisa em Educação. E isto não é pouca "porcaria”!

- Por isso, atenção! Em face dessa arbitrariedade, inerente à pesquisa, cada um precisa avaliar onde, em que porção do território, problemática, temática educacional, pode se autorizar a pesquisar. Onde pode se movimentar, com mais facilidade, buscar as obras mais significativas, trançar conceitos, ter insights e justificá-los, etc. Ou seja, em outras palavras: escolhe-se aquilo que, até chegar no Mestrado ou Doutorado, mais se estudou, viveu, preocupou, pensou, praticou. Pois não existe nenhum "superorientador" que possa guiar o tempo inteiro cada um e todos os orientandos, na totalidade dos caminhos que ele precisa percorrer. Em outras palavras, ainda: não é aconselhável inventar "coisas totais", ou "de última hora", ou uma atividade de pesquisa, que seja "inteiramente" nova.

- Mas, voltando às benditas “unidades". Elas nascem, só podem nascer, como gosto de dizer, do encontro das duas rãzinhas que pulam da teoria e do objeto bruto - nem tão "bruto" assim, aliás, porque já lido e re-dito com os óculos teóricos. Tenho comprovado que as mais produtivas unidades são as geradas deste modo. Por um motivo bem simples: temos "munição" nas duas gavetas, na do objeto bruto e na gaveta teórica. 
- Quanto às “duas rãzinhas”. Em verdade, as tais "rãzinhas”, em vez de duas, são três. Por um motivo cristalino: na criação das unidades analíticas, junto com a da teorização e com a que emerge do discurso que estamos estudando, "pula" também, e de modo às vezes decisivo, muito do que é nosso, do que trazemos, ensinamos, vivemos, gostamos, nos apaixonamos. Por isto, esta terceira rãzinha eu a chamei de "rãzinha do gosto". Atentem para ela, porque é um pedacinho de nós, de nossa prática profissional, de nosso estilo de existência, de nosso modo de pensar, significar e viver a vida, enfim.

- Retomando: somente se temos as unidades analíticas, na hora da Proposta, é que poderemos mostrar à Banca algo do que será mais e melhor trabalhado na Tese/Dissertação.

- Caso contrário, não. Caso contrário, prefira apenas indicar o rol das possíveis unidades analíticas. Porque isto também é aceito: não desenvolver nenhum exercício analítico e apenas apresentar, referir as unidades, sob as quais se vai analisar o objeto pesquisado. Então, descreva tais unidades na "carta de intenções”, que é também uma "carta de compromisso".

\section{CARTA DE "INTENÇÕES/COMPROMISSO"}

- Esta costuma ser a parte final da Proposta, onde escrevemos o que vamos fazer. Diante de tudo o que foi escrito, daqui para a frente, com esses viáticos, vamos realizar tais e tais coisas, deste e daquele jeito.
- Aqui são apresentados o "método", as “fontes", o apontamento de algumas unidades analíticas, que não foram desenvolvidas, apenas indicadas, etc. Às vezes, são reunidas, sob a forma de sínteses, algumas coisas que ficaram dispersas no texto.

- Esta também é uma seção conclusiva, mas que não pode ter um "tom" de conclusão. Ao contrário, de que ser um riacho que corre, um canal que joga para frente, um rio que deixa abertos os rumos, para que os membros da Banca sintam-se à vontade para fazer o que se espera que façam: avaliem, sugiram, indiquem rotas. A Banca tem de se sentir "convidada" a entrar em sua Proposta. Por isso, sua escritura tem de levá-la a produzir sobre/entre/com o seu texto. Se o seu texto for onipotente, cheio de razão, pleno de certezas e tal, nada disso vai acontecer. Então, para que Banca Examinadora?

- Esta é também uma seção onde se selam os compromissos de pesquisa. Ao menos até, se for o caso, eles serem des-guiados pela arguição e problematização da Banca.

\section{OUTRAS DICAS}

Se a sua leitura chegou até aqui é porque interessou. Então, aqui vai mais.

1. Aprenda a abrir/criar subseções. Elas, sempre, permitem enfocar melhor o que estamos escrevendo. Seja na revisão teórica, na apresentação do objeto bruto, no exercício

EM TESE BELO HORIZONTE $\quad$ v. $22 \quad$ N. $1 \quad$ JAN.ABr. 2016 CORAZZA. Manual infame... mas útil, para escrever uma boa proposta [...] P. 95-105

\section{Teoria da literatura e Ensino de Literatura}


analítico. Esta é uma arte importante para quem escreve e também para quem lê. Muitas vezes, não conseguimos identificar as subseções que, inclusive, já estão presentes em nosso texto, que vão acontecendo à medida que escrevemos. Por isto, um olhar externo, como o da Orientadora e do Grupo de Orientação, ajuda e muito.

2. Atente para os títulos, desenvolva a arte de criar títulos Os melhores costumam ser os mais "finos", de um certo modo, irônicos, lúdicos, instigantes - no sentido de que já sinalizam para as deformidades que se pretende realizar no objeto bruto. Eles devem saltar das duas gavetas, do objeto e da teoria, ao mesmo tempo. Bem como saltar do gosto, do prazer, do divertimento que é criar, da vontade de dar nomes diferentes, próprios, a nossas "crias", ao que estamos criando.

3. Uma outra arte que é preciso desenvolver é a da montagem final da Proposta. Implica sensibilidade e astúcia, diante do conjunto. O que combina? O que tem o mesmo tom? O que é melodioso? E o que não é? Juntar, apartar. Este é o movimento duplo. Muitas vezes, nos perdemos na escrita ela nos extravia. Neste momento, porque já estamos saturados dela, sempre é bom um outro olhar e outra escuta a teu texto. Alguém em quem confiamos, como bom leitor, pode auxiliar, uma amiga, um namorado, uma amante, até um inimigo. Alguém arguto, de preferência, que saiba "escutar" o texto, como um competente analista.
4. Outra questão importante é a escolha do "formato" da Proposta. Caso se esteja trabalhando, metodologicamente, com conceitos de autor/autores que sejam propícios, que forneçam elementos/linhas/cores para um novo "desenho" - tais como a cartografia de Deleuze \& Guattari, a desconstrução de Derrida, a arqueologia de Foucault, os aforismos de Nietzsche -, por que usar os nossos formatos clássicos e tão repetitivos? Por que usar o "esqueleto" deste Manual infame... mas útil..., por exemplo? Deve-se aproveitar o que os autores inventaram para inventar também, para ousar.

5. Aprenda, no texto, a se apropriar de ideias, argumentos, conceitos. Torne-os "seus". Evite o excesso de citações em destaque, e os malfadados "conforme fulano...", "para beltrano...". Use aspas, em pequenos fragmentos, em frases-chaves, somente naquilo que não dá para fazer e ser "seu". Ao agir assim - como um "bom ladrão" -, você se obrigará a entender melhor a argumentação, a incorporá-la a seu objeto de pesquisa, a escrever mais, inclusive. E estará, então, minimamente, abrindo as "janelas" para elaborar uma nova, uma diferente, uma outra teorização. Porém, cuidado, para não botar o seu objeto de pesquisa na boca do autor escolhido! Para o "coitado", talvez seu objeto nem existisse, nem fosse questão. Imite como fazem, nesta direção, os pesquisadores/escritores/intelectuais que você admira muito. Então, ficará tudo bem. 
6. A última dica: "demonstre" sempre e bastante, demonstre exaustivamente as coisas de seu objeto, em junção com a teoria. Não "aplique" a teoria, seja um "usuário" competente dela, use-a para demonstrar as coisas novas, que apenas nascem da interação com o seu objeto. A análise tem de ser, acima de tudo, demonstrativa, nunca uma exemplificação ou ilustração para a teoria estudada. Os autores, com os quais você pesquisa, não precisam que você comprove o quanto eles tinham razão. Eles já sabiam disso, ao inaugurarem novos modos de dizer e de olhar as coisas do mundo. E você só fará isso, ou um pouquinho disso, se demonstrar esses novos modos com que você está olhando e dizendo o seu objeto.

\section{DUAS PEQUENAS “PÉROLAS"}

1. PARA ESCREVER A DISSERTAÇÃO OU TESE

Escreva um texto que esteja pronto para ser publicado. Não coloque, nele, tudo o que for excessivamente acadêmico: pilhas de cansativas citações em destaque, centenas de notas de rodapé, que doem os olhos e que ninguém tem obrigação de ler, tediosas revisões bibliográficas que, se o leitor quiser, vai ao autor original, etc. Deixe o texto fluido, articulado, legível, como um livro, que é o que ele deve ser. Afinal das contas, escreve-se para os outros do mundo, não? Quanto mais "pronto" estiver para voar, melhor. Mais chances você terá de publicá-lo, sem precisar ficar meses faxinando, cortando, acrescentando, articulando, tornando-o publicável.
2. COMO SOBREVIVER ÀS SESSÕES DE DEFESA

Olhe: você sabe mais sobre o seu trabalho do que ninguém, certo? Portanto, defenda-o, digna e firmemente. O Examinador pode ter as suas razões, quando lhe critica, porque conhece profundamente o autor ou a teoria em questão, por exemplo. Só que é você quem "conhece" mais e melhor o que você "fez" com aquilo tudo, na análise do seu objeto de pesquisa.

Mas não seja prepotente nessa hora, nem em nenhuma outra. Tenha a desejável humildade intelectual, mas também não seja frouxo. Não morda nem rasteje. Não deixe questões sem exame. Agradeça, se não souber responder, diga que vai pensar, que não havia anteriormente contemplado aquela questão. Ou, que sabia daquilo, mas optou por não usar, por julgar mais produtivo usar tal e tal ferramenta analítica, por tal e tal motivo. Se for o trabalho final, diga que aquilo que está sendo apontado como estando frágil deverá ser fortalecido, sim, em pesquisas e produções vindouras, pois aquele, com certeza, não será o seu último trabalho, etc.

Em poucas palavras: faça "bonito", como Mestre ou Doutor que você quer ser, pois vem trabalhando para isso. Aproveite o espaço da Sessão de Defesa para continuar "produzindo" sobre o seu texto, pois é uma instância muito importante para a sua pesquisa: a hora em que ela sai do ninho, que é o da Orientação, e começa a ganhar o mundo, o tempo, a história. Em suma, seja firme, mas também terno. E isto é difícil de praticar, embora fácil de lembrar e dizer, desde o Che.

EM TESE BELO HORIZONTE $\quad$ v. $22 \quad$ N. 1 JAN.ABR. 2016 CORAZZA. Manual infame... mas útil, para escrever uma boa proposta [...] P. 95-105

Teoria da literatura e Ensino de Literatura 


\section{RECEITA DE UMA TESE FOUCAULTIANA}

1. Misture em sua cabeça (a mistura deve ficar bem seca):

a. 3 xícaras de porcelana do melhor Foucault da época pós-estruturalista

b. 1 envelope de fermento arqueológico (o mais profundo que encontrar, sem ter de passar pelos horrores da Arqueologia do saber)

c. 1 colher de chá de sal-da-vida (Mas só o sal, quanto à vida, propriamente dita, esqueça! Enquanto estiver fazendo esta receita, você não viverá, a não ser uma vez por semana - e olhe lá, já é lucro! Só que, aí, já estará tão cansado que, logo, logo, se embriagará, mesmo que não esteja tomando um "30 anos". A comida lhe dará azia, gastrite, até úlcera. $\mathrm{O}$ antológico filé de linguado com alcaparras do Gambrinus terá gosto de pirão. O filme lhe trará novas - e disparatadas, sempre inúteis! - ideias para adicionar à sua tese. A Bienal do Mercosul lhe mostrará que voce não é, nunca foi, não será, não tem a mínima chance de ser criativo. O jazz do Café Majestic será ouvido como se fosse pagode e as músicas do Bar do Nito como pura perda de tempo. As conversas com os amigos lhe parecerão terrivelmente triviais e os próprios amigos, tremendamente banais. O cigarro terá o amargor do fel, além de você ficar cheio de picumã. O café espresso, que você tanto curte, terá gosto de cevada braba. Você terá de dominar os seus impulsos zoocidas, quando os três cachorros e os cinco gatos lhe pedirem comida. O próprio fazer-amor terá sabor de um perigoso suplemento, como diria Derrida, que o desvia de seu verdadeiro amódio atual: a tal da tese. E a maior de todas as desgraças é que você ficará, nesta única vez na semana, com uma vontade imensa, inegociável, quase incontrolável, de regressar aos livros, às notas manuscritas, ao teclado, a seu texto, em suma.)

d. 1 colher de chá de bicarbonato de sódio (não para que a massa cresça, mas para combater aquela maldita queimação estomacal)

2. Bata, bata, bata... no Processador (seu cérebro devastado, com vários neurônios mortinhos), na Batedeira (que é um dispositivo de bater, merecedor de uma genealogia, tipo Vigiar e bater...), ou à Mão (se ela não estiver entrevada pela tendinite, epicondilite, todas as ites), até formar uma espécie de geleia real (não soberana, pois este tipo de poder já era.. Era? E FFHHCC, o Príncipe?). Assim, você deverá obter: uma espécie de caldo, como o cultural; um creme, como os de beleza (a qual, aliás, você vem gradativamente perdendo, dia e noite, noite e dia, mais à noite, nos serões, horas e horas debaixo da irradiação das fluorescentes); um mel, como o da abelha, muito, mas muito mais profícua do que você; 
etc. Inevitavelmente, o ponto certo de tal mistura somente é atingido, em função da liga incolor, ligeiramente salgada, formada por todas as lágrimas que você chora, chorou, e chorará, durante as grandes e pequenas revoltas, crises, bloqueios, e os surtos intermináveis dos quais a receita é feita.

3. Adicione 1 xícara de açúcar (no mais das vezes, pode-se usar vinagre mesmo, por seu caráter inerente ao preparado)

4. 5 colheres de sopa de margarina (mas não pense que pode ficar de colher na mão, já que os dias, semanas, meses, anos em que se faz essa receita não são dias de sopa, mas de churrasco mesmo, daqueles esturricados, queimados, carvãozinho) - substitua por manteiga, se tiver coragem. Antes, faça todos os exames laboratoriais necessários, para verificar as taxas de colesterol - total, HDL, LDL -, triglicerídeos, creatinina, fosfatase alcalina, anticitomegalocirus, HIV, pois todas as suas taxas devem estar alteradíssimas. Reveja o filme $O$ último tango em Paris, embora possa ser substituído por $O$ império dos sentidos, embora eu não me lembre de manteiga por lá, e esta associação tenha sido apenas livre, e tome a sua decisão, entre margarina e manteiga, já que você está tendo de tomar, parece, todas as decisões mais importantes do mundo.

5. Caso o(s) filme(s) e os resultados dos exames tenham produzido bons efeitos em você, acrescente 2 ovos (de galinha, de preferência, nada de inventar ovos humanos) à mistura anterior e bata mais um pouco (vontade de bater é que não falta!)

6. Junte a mistura seca à molhadíssima e acrescente $1 \frac{1}{2} 2$ xícara de leite (de vaca, cabra, cobra - afaste-se do leche de su propia madre). Misture isso (do jeito que puder, a estas alturas do campeonato), mas sem bater demasiadamente, apenas para formar uma massa homogênea (embora você já esteja disforme)

7. Agora, sim, é chegada a hora de botar em movimento sua identidade mestiça, fronteiriça, estrangeira, estranha, e isolar as heterogeneidades, delimitar as rupturas, descontinuidades, deslocamentos. Em poucas palavras, meu deus: definir AS UNIDADES DE SUA ANÁLISE. O perigo não mora ao lado, mora aqui. Faça isso com coragem, sulcando a massa, com variadas microfísicas de poder, todas as vontades de saber de que for capaz, histórias muitas histórias, usando os poucos prazeres que lhe sobraram, sem cuidar nadica de nada de si. Afinal - e já não era sem tempo (esta frase que nenhuma criatura que fala outra língua entende) -, a doença do corpo, a mental, a loucura se avizinham. Já não se escutam mais as palavras, nem se olham as coisas, pois elas não fazem mais nenhum sentido. Todas as três sexualidades, bem como as outras, não publicadas, impublicáveis, foram para as cucuias. Da prisão não se escapará, pois ainda matamos alguém, deixando para publicação póstuma um dossiê do tipo Eu, que fazia a tese, degolei minha mãe, meu pai, minha irmã,

EM TESE BELO HORIZONTE $\quad$ V. $22 \quad$ N. $1 \quad$ JAN.-ABr. 2016 CORAZZA. Manual infame... mas útil, para escrever uma boa proposta [...] P. 95-105

\section{Teoria da literatura e Ensino de Literatura}


meu irmão, meu marido, os três filhos, a empregada, a faxineira o vizinho, et alii. Sorte nossa, apesar de nossas pós-críticas, que o poder disciplinar criou o asilo e a psiquiatria e a clínica e o hospital: salvarão nossos corpos e libertarão nossas sofridas almas de intelectuais, resgatando, de suas relações com o poder do PPGEDU, da CAPES e do CNPq, sua função autêntica e legitimamente política. Entretanto, do suplício, igualzinho ao de Damiens, não escaparemos. Pois, afinal de contas, estamos ou não estamos fazendo uma tese? Somos, ou não, mulheres e homens criminosos, subversivos, anormais, ao nos propormos a ser autores?

8. A esses efeitos, que são de superfície, não se preocupe, acrescente 1 xícara de nozes (elas têm, sim, a forma do seu cérebro!) e 1 xícara de passas secas (pode ser daqueles seus neurônios, para sempre descartados). Coloque nas forminhas e leve ao forno médio (como variação, pode-se ir a uma fogueira de Sabá), até dourar todas as camadas sedimentares (enquanto isto, dê uma sesteada, pois está chovendo de novo - é o monstro do El Niño, ou a monstra de sua irmã, que espalham furores e flagelos no Planeta, tal como o de meter a gente a fazer uma tese -, e a madrugada será longa, até o alvorecer, como todas as outras).

9. Por fim, leve o resultado dessas ações sobre suas próprias ações para o Grupo de Orientação e, em companhia da Orientadora e dos colegas, deguste todas as alegrias a que você tem direito. Caso avalie que vai precisar, tome 6 Prozacs, uma hora antes, para evitar o repé, o bode, a pós-orgia. E, bom proveito! O que dá gosto regala a vida!

$* * *$

Obs.: Não existem variações para esta receita. Se alguém as descobriu, até hoje não contou. Ou, então, é daqueles metidos a besta, que dizem que a coisa toda sai na urina, sendo, portanto, falsa a receita. Não acredite em nenhuma palavra desse teor. Perdoai-o, porque o cara não sabe o que diz, nem - o que é mais sério - o que faz!
EM TESE
BELO HORIZONTE
v. 22
N. 1
JAN.-ABR. 2016
CORAZZA. Manual infame... mas útil, para escrever uma boa proposta [...] $\quad$ P. 95-105

Teoria da literatura e Ensino de literatura 